\title{
A NOVA GESTÃO PÚBLICA NA INGLATERRA: A PERMANENTE INSTABILIDADE DA REFORMA NEOLIBERAL
}

\author{
David Hall \\ Helen M. Gunter ${ }^{*}$
}

\begin{abstract}
RESUMO: A reforma da educação na Inglaterra tem sido intimamente associada a um programa mais amplo da nova gestáo pública, centrado na reforma dos serviços públicos. Este artigo analisa as características deste programa de reformas inspirado na NGP, tendo em vista que o sistema educacional inglês se deslocou de uma forma cívica e de proteçáo social ("cívico-welfarista") para um modo em que o neoliberalismo despontou em ascendência. Atençáo particular é dada tanto aos aspectos centralizadores da reforma, em que tem havido um acentuado aumento na intervenção do governo central na educação, quanto aos aspectos descentralizadores da reforma, incluindo a criação de escolas como unidades de negócios e a mercantilização da educação em termos mais gerais. As origens das reformas estáo situadas em uma construção discursiva de uma crise educacional, inspirada na Nova Direita, que encontrou posterior expressão em uma série de alterações na legislação que emergiram de e cimentaram um consenso educacional trans-político-partidário que já perdura por mais de trinta anos neste contexto. Este artigo examina os efeitos dessas reformas da NGP na educação na Inglaterra, e as continuidades e descontinuidades entre as diferentes administraçóes políticas, considerando que a Inglaterra passou por sucessivas ondas de reformas até chegarmos a um período pós-NGP. Concluímos que a permanente instabilidade do sistema educacional inglês pode ser identificado nas tensóes que atingem o próprio âmago do processo da NGP, de formas que, antecipamos, continuarão a perturbar um setor rapidamente privatizador.
\end{abstract}

Palavras-chave: Nova gestão pública; Sistema inglês de educação; Neoliberalismo; Inglaterra.

\footnotetext{
* University of Manchester, Faculty of Humanities, School of Environment, Education and Development. Manchester, United Kingdom. E-mail de contato: dave.hall@manchester.ac.uk.
} 


\section{NEW PUBLIC MANAGEMENT IN ENGLAND: THE PERMANENT INSTABILITY OF NEO-LIBERAL REFORM}

ABSTRACT: The reform of education in England has been closely associated with a wider programme of new public management focused upon the reform of public services. This article analyses the characteristics of this NPM inspired reform programme as the English education system has moved from a civic-welfarist mode to one in which neo-liberalism has emerged in the ascendancy. Particular attention is paid both to the centralising aspects of reform where there has been a marked increase in central government intervention in education and the decentralising aspects of reform including the creation of schools as business units and the marketization of education more generally. The origins of the reforms are located within a New Right inspired discursive construction of an educational crisis that found later expression in a series of legislative changes that arose from and cemented a cross-politi, nocal party educational consensus that has now endured for over thirty years in this context. The article examines the effects of these NPM reforms on education in England and the continuities and discontinuities between different political administrations as it has moved through successive waves of reform to a new post-NPM period. It concludes that the permanent instability of the English education system can be located within tensions that go to the very heart of the NPM process itself in ways, it is anticipated, that will continue to bedevil a rapidly privatising sector.

Keywords: New public management; English education system; Neoliberalism; Civic-welfarist.

\section{LA NOUVELLE GESTIÓN PUBLIQUE EN ANGLETERRE: UNE INSTABILITÉ PERMANENTE DE LA RÉFORME NÉOLIBÉRALE}

RÉSUMÉ: La réforme de l'éducation en Angleterre a été étroitement liée à un programme plus large de la nouvelle gestion publique, basé sur la réforme des services publics. Cet article analyse les caractéristiques de ce programme de réforme inspiré par la NGP, étant donné que le système éducatif anglais est parti d'une approche civique et de protection sociale (civique-welfariste) vers une approche où le néolibéralisme a émergé en ascendant. On a attribué une attention particulière aux aspects de centralisation de la réforme, où il $\mathrm{y}$ a eu une augmentation marquée de l'intervention du gouvernement central en matière d'éducation, et également aux aspects décentralisateurs de la réforme, y compris la création d'écoles en tant qu'unités de marchés et la marchandisation de l'éducation en termes plus général. Les origines des réformes sont situées dans une construction discursive d'une crise de l'éducation, inspirée par la Nouvelle Droite, qui a trouvé dans une série de changements dans la législation qui ont fait apparaître, bien que consolidés, un consensus éducatif trans-politique-partidaire qui perdure depuis plus de trente ans dans ce contexte. Cet article examine les effets des réformes de la NGP 
dans l'éducation en Angleterre et les continuités et les discontinuités entre les différentes administrations politiques, estimant que l'Angleterre a connu des vagues successives de réformes pour atteindre une période post-NGP. Nous concluons que l'instabilité permanente du système éducatif anglais peut être identifiée dans les tensions qui affectent le cœur même du processus de la Nouvelle Gestion Publique de formes qui, prévoyons-nous, continueront à perturber un secteur de privatisation rapide.

Mots-clés: Nouvelle gestion publique; Angleterre; Réforme de l'éducation; Le néolibéralisme.

\section{Introdução ${ }^{1}$}

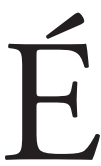

importante asseverar que a nova gestão pública (NGP) não é tão recente na Inglaterra. Como Hood e Peters (2004) apontaram há mais de uma década, é um fenômeno que agora está em sua meia-idade, tanto que o termo final da meia-idade parece ser agora um descritor mais apropriado. A principal indicação da maturação da NGP, neste contexto, é que ela tem sido continuamente desenvolvida e reforçada, atravessando uma gama de governos, tendo início com as administrações lideradas por Thatcher [N.E.: Margaret Hilda Thatcher, Primeira-Ministra do Reino Unido, no período de maio de 1979 a novembro de 1990] de 1979 a 1990, até a coalizão Conservadora/Democrata Liberal de 2010 a 2015. Neste artigo, contudo, argumentamos que a longevidade e a continuidade da NGP na Inglaterra não deveriam nos distrair nem das distinções entre as diferentes administrações políticas pela forma pela qual buscaram reformar a educação, nem de suas instabilidades dentro do sistema educacional inglês, geradas pelos processos de reforma. De forma semelhante, ainda que o foco das reformas da NGP tenha recaído sobre os serviços públicos, ela sempre atuou, ao menos em parte, como portadora de práticas derivadas do setor privado. (CLARKE; NEWMAN, 1997) Aliada a isso, a privatização da educação emergiu fortemente como a principal característica das reformas educacionais inspiradas na NGP na Inglaterra, (BALL, 2007) a ponto de, atualmente, o termo pós-NGP (CHRISTENSEN; L/ÆGREID, 2011; DUNLEAVY et al., 2005) ser considerado como um descritor mais adequado na Inglaterra. Desta forma, argumentamos que o termo "público" no contexto da NGP na Inglaterra não deveria desviar nossa atenção da reafirmação do "privado" nos espaços educacionais anteriormente ocupados, embora temporariamente, a partir de uma perspectiva contemporânea, pelo "público".

Além disso, a noção de "gestão", dentro das instituiçôes educacionais contemporâneas na Inglaterra, foi substituída pelo termo "liderança”. 
(HALL et al., 2013) Neste caso, no entanto, o uso do termo liderança não deveria desviar nossa atenção da contínua ascendência da gestão e do gerencialismo na organização das instituiçóes educacionais. (HALL, 2013) Desta forma, as coisas nem sempre são o que aparentam no que tange à reforma educacional inspirada pela NGP na Inglaterra, e este artigo oferece um relato das complexidades dessas reformas e das bases para a resultante permanente instabilidade para os jovens, profissionais da educação e instituiçóes educacionais.

\section{A emergência da Nova Gestão Pública dentro do Reino Unido}

Fundamental à emergência da Nova Gestão Pública (NGP) no Reino Unido foi a eleição do Partido Conservador em 1979, sob a liderança de Margaret Thatcher, que, à época, havia emergido como uma liderança chave para a Nova Direita. Embora o welfarismo pós-II Guerra Mundial anteriormente dominante tenha se encontrado cada vez mais sob tensão nos anos 1970 no Reino Unido (GAMBLE, 1988), não foi senão até a formação de um governo liderado por Thatcher que esta configuração política em particular tornou-se alvo de ataques permanentes. Entre os anos de 1945 e 1979 a política britânica foi dominada por um Partido Trabalhista e pelo One Nation Conservatives com inclinaçóes welfaristas, que defendiam intervençóes econômicas e sociais por parte do Estado, de forma a lidar com a pobreza e manter o poder da comunidade. Os partidários do One Nation Conservatives apoiavam amplamente a noção de proteção social e conseguiam atuar dentro de um consenso pós-guerra welfarista. Sua subsequente marginalização dentro do Partido Conservador, sob a liderança de Margaret Thatcher, resultou em uma dramática alteração de curso para o Reino Unido.

Por detrás desta tentativa de deslocar o welfarismo pós-guerra no Reino Unido subjazem duas vertentes do pensamento da Nova Direita. Primeiramente, foi a emergência do neoliberalismo. Embora com um marcado distanciamento do Butskellismo ${ }^{2}$ do welfarismo pós-Guerra de inspiração Keynesiana implantado durante os anos 1950 e 1960, o neoliberalismo pode ser visto como um renascer discursivo de uma abordagem profundamente enraizada e economicamente liberal para a resolução dos problemas sociais e econômicos no Reino Unido (BRIGGS, 1961), ao ponto de, a partir de uma perspectiva contemporânea, após o que somam agora mais de 35 anos de um domínio discursivo inspirado no neoliberalismo (HARVEY, 2005), sobre a economia e a política, é a emergência do Estado welfarista, ao invés da revitalização do Estado Liberal sob o neoliberalismo, que pode agora se apresentar como um episódio aberrante.

Desta forma, a rápida emergência do neoliberalismo no Reino Unido nos anos 1980 pode ser vista como uma revitalização de uma tradição previamente consagrada de liberalismo econômico nos assuntos públicos em termos 
mais gerais que, uma vez reativada em sua neo-forma retrabalhada, ofereceu uma base rica e fértil para sua rápida disseminação em diferentes aspectos da política, sociedade, economia e cultura do Reino Unido. Em segundo lugar, as condiçóes que, no Reino Unido, resultaram na eleição de um governo inspirado na Nova Direita, também estavam sendo vivenciadas por todas as chamadas economias industriais avançadas do Ocidente e outras regióes do mundo. O otimismo da alta modernidade, as promessas associadas de "aquecimento da revolução tecnológica" (WILSON, 1964) e a capacidade de planejamento estratégico racional, aliados a intervençôes lideradas pelo Estado para capturar, para seus cidadãos, as promessas de rápidos avanços na Ciência e Tecnologia, haviam sido substituídos, após períodos de turbulência ligados, por exemplo, à crise do petróleo da OPEC de 1973, por um discurso bem diferente.

Este novo discurso enfatizava as ineficácias e ineficiências dos governos e os custos excessivos de se manter um Estado assistencialista e foi diretamente associado aos principais programas de reforma pública em uma gama de países que incluía, na Europa, a Holanda, a Suécia e o Reino Unido e, em outras partes do mundo, a Austrália, o Canadá, a Nova Zelândia e os EUA (POLLITT; BOUCKAERT, 2000). Esses programas de reforma foram mais tarde coletivamente descritos e caracterizados como a Nova Gestão Pública e, em seu âmago estavam as tentativas, agora reconhecidas como sendo o cerne da NGP (CLARKE; NEWMAN, 1997), de tornar a atividade governamental mais empresarial, por meio do transplante de técnicas de gestão e da cultura e valores empresariais do setor privado. Desta forma, o surgimento de discursos neoliberais dentro da NGP não era algo peculiar ao Reino Unido. No entanto, tomadas em conjunto, várias características no contexto do Reino Unido, mais particularmente no contexto da derrota política do One Nation Conservatism dentro do Partido Conservador, a associada influência da Nova Direita, antigas tradiçóes de um Estado liberal e uma crise para a democracia social mais vivenciada em geral no Reino Unido (ao menos em parte como um desencanto com as intervençóes lideradas pelo Estado), seguindo as crises econômicas da década de 1970, combinaram para oferecer o que é, em retrospecto, um conjunto extremamente promissor de circunstâncias para a propagação de uma intensa e inexorável forma de neoliberalismo, bem adequada a uma versão agressiva da NGP.

\section{A NGP e sua emergência na educação na Inglaterra}

Em relação à educação na Inglaterra, esses eventos mais amplos descritos anteriormente encontraram expressão em uma "crise" discursiva que, não surpreendentemente, dado o exposto anteriormente, também emergiu nos anos 1970. Foi uma crise baseada em preocupaçóes com a queda nos padróes educa- 
cionais em escolas mantidas pelo Estado que haviam sido alimentadas via uma série de "Black Papers" oriundos do Partido Conservador que, de formas variadas defendia o controle das escolas por parte dos pais, vouchers educacionais, escolha das escolas por parte dos pais e a competição entre as escolas. (COX; DYSON, 1969; COX; BOYSON, 1975) As preocupações expressas nos Black Papers estavam principalmente centradas nos métodos de ensino "progressistas" (a mudança para a escolarização abrangente ou comum teve início no final dos anos 1950), em percepçóes de níveis inapropriadamente altos de autonomia dos professores e falta de responsabilização por parte dos professores. Eles culparam a educação progressista pela falta de disciplina nas escolas e mesmo os tumultos dos alunos nas universidades. Foi conferida uma expressão totêmica a essas preocupaçóes nos eventos amplamente relatados ligados a alteraçóes pedagógicas radicais na escola William Tyndale em Londres durante os anos de 1974-76. (DAVIS, 2002)

É lógico que tanto os Black Papers, como o caso da escola William Tyndale, resultaram em muitos comentários e conjecturas em uma mídia impressa arrebatadoramente de direita (WALLACE, 1993), no sentido de ativamente buscar espalhar o pânico e o medo em relação à educação pública. Tal crise discursiva atingiu seu ápice quando um inquérito quase judicial sobre os eventos na escola William Tyndale legitimou a ideia de que os professores não apenas possuíam muita autonomia, mas também, que estavam perseguindo meios subversivos. (WHITTY; MENTER, 1988) Tal fato ganhou força significativa em outubro de 1976, quando o então Primeiro Ministro do Trabalho, James Callaghan, em um agora famoso discurso na Faculdade de Ruskin, endossou a visão da educação pública baseada no déficit que emergia durante a crise e foi além, ao relacionar o percebido declínio nos padrôes educacionais a uma diminuição da competitividade econômica internacional do Reino Unido. (CALLAGHAN, 1976)

Isso prenunciava o que se tornou, pelo menos durante os trinta anos seguintes, uma apologia repetida infindavelmente pelos elaboradores de políticas de elite na Inglaterra: a posição de que o fracasso educacional estava intrincavelmente ligado ao fracasso econômico nacional. ${ }^{3}$ Assim, o poder dessa crise discursiva, da forma como era refletida em seu apelo multipartidário, pode ser visto como tendo fornecido um momentum significativo para a subsequente emergência de um consenso político incrivelmente resiliente em relação à reforma educacional, no qual as invocaçóes para o aprimoramento dos padróes educacionais, derivadas de um discurso da Nova Direita, iriam ocupar o espaço central. Essa invocação discursiva se tornou o ponto de mobilização para uma série de esforços de modernização por parte de administraçóes Conservadora, da New Labour e de Coalizão. 


\section{O Ato da Reforma Educacional de 1988}

Em 1988, um novo Ato de Reforma Educacional se desenrolou sob o então Secretário da Educação, Kenneth Baker. Da mesma forma que as reformas educacionais precedentes dos anos 1980, o Ato de 1988 é visto aqui como uma resposta direta à "crise" discursiva da educação pública que teve início nos anos 1970 e que emergiu, predominantemente, da Nova Direita, mas o qual, a esta altura, como observado anteriormente, tinha maior força, ao menos em termos de sua localização, dentro dos partidos Conservador e Trabalhista. Suas principais estipulações apelavam diretamente às preocupaçóes expressas nos Black Papers e ecoavam tão fortemente na mídia impressa. O Ato oferecia uma base consideravelmente ampla para um conjunto de reformas que iriam se inscrever em gerações de crianças e desencadear uma subsequentemente "revolução permanente" (POLLITT, 2007) da reforma educacional e de modernização. Foi uma tentativa de re-cultivar e re-estruturar as instituiçóes educacionais e aqueles que nelas trabalhavam e, como poderá ser visto mais adiante neste capítulo, forneceu a sustentação vital para posteriores ondas de reformas educacionais.

Algumas das provisóes chave que emergiram do Ato de 1988 incluem:

- A centralização do currículo e da avaliação nas escolas por intermédio de um Currículo Nacional, baseado principalmente em disciplinas acadêmicas tradicionais, avaliadas por meio de testes nacionais em quatro instâncias, entre as idades de 6 e 16 anos;

- A mercantilização da escola, tendo como conseqüência a competição entre as escolas por alunos, com base na escolha dos pais. Muito dessa competiçáo era baseada nas tabelas de ligas das escolas, compiladas a partir de conjuntos de dados nacionais, vinculados a classificaçóes com base nos testes dos alunos;

- A criação de escolas como se fossem unidades de negócios locais, via gestão financeira no âmbito institucional;

- Apoio a interesses privados na educação, por intermédio da criação de escolas fora do controle local eleito democraticamente e por meio de apoio financeiro oriundo de patrocínio privado.

Este Ato é tido como a encarnação das ideias da Nova Direita sobre a educação, correspondendo intimamente, em muitos aspectos, à NGP, e revelando tensões entre as vertentes neoliberal e neoconservadora deste movimento. A ênfase na escolha, mercados e competição/concorrência, além de tentativas de criar escolas independentes do sistema central, são vistos aqui como reflexo das preferências neoliberais e ambiçóes dos reformadores, ao passo que o controle central sobre o currículo e a avaliação, destinado a se opor ao progressismo educacional e promover padróes educacionais, é concebido como o reflexo das demandas mais neoconservadoras dos reformistas. Tomado em seu conjunto e, em linha com 
as reformas mais amplas do serviço público desse período, este Ato representou uma tentativa de deslocar a abordagem cívica e de bem-estar social em relação à escolarização, que tinha passado a dominar o período pós-guerra, com novos arranjos estruturais que pretendiam ter um impacto radical nas escolas, professores e jovens.

Embora tenha havido discordâncias dentro do Partido Conservador entre os neoliberais e os neoconservadores durante este estágio de fundação (WHITTY; MENTER, 1988), sobretudo no que diz respeito à extensão e cobertura do Currículo Nacional, as tensóes ideológicas em termos da reforma educacional, entre esses dois grupos, naquele momento, podem ter sido um tanto exageradas. Enquanto os neoconservadores enfatizavam a restauração da autoridade e a imposição de disciplina social, devido ao liberalismo que se viu crescer durante os anos 1960, e os neoliberais enfatizassem a importância dos mercados como o principal mecanismo por meio do qual o progresso seria alcançado, ambos estavam comprometidos em recuar as fronteiras do Estado a uma gama de funçóes estritamente limitada. De forma correspondente, o Ato de 1988, com suas provisóes neoliberais, forneceu as bases para um tipo de sistema educacional muito diferente, no qual o papel do Estado podia ser bastante reduzido.

Para os jovens e os professores, o Ato de 1988 veio a ter implicaçóes dramáticas. A criação de um Currículo Nacional, bem como de testes nacionais a ele associados, tornaram possível um sistema educacional mais legível (SCOTT, 1990), no qual as vastas quantidades de dados, baseados em métricas, se tornaram disponíveis às diferentes partes envolvidas. Esses dados se referiam principalmente ao desempenho dos alunos em relação aos níveis de aproveitamento/rendimento criados no Currículo Nacional. Em conjunto com um sistema mercantilizado baseado na competição (dentro das instituições educacionais e entre elas), ele se tornou a base estatística sobre a qual não somente quase-mercados educacionais foram possibilitados, mas também se tornou a base para tentativas altamente determinadas e gestionárias de elevar o nível de desempenho dos alunos, do professor e da escola. Neste novo regime de desempenho, os alunos teriam conhecimento de (e seriam frequentemente lembrados de) seus níveis de rendimento em relação aos objetivos definidos de acordo com normas nacionais. (WILIAM et al., 2004)

Os professores passaram a ser geridos por meio de dados em termos da turma/classe, e as escolas, a despeito das relaçôes bem estabelecidas entre seu desempenho institucional e a relativa vantagem sócio-econômica de seus alunos (OZGA, 2009; PERRYMAN et al., 2011), seriam julgadas de acordo com dados brutos de desempenho publicados nas Tabelas de Ligas das Escolas. Os professores viriam a experimentar não apenas uma perda substancial de autonomia, mas também formas de terror (BALL, 2003), que se manifestavam de formas variadas como ansiedade, estresse e danos a si próprios. Isso foi revelado em uma performatividade ligada à ameaça de inspeçóes pelo corpo de inspeção nacional, OFSTED, 
e gestão de desempenho com base em métrica conduzindo a formas mais restritas (EVETTS, 2009) de profissionalismo. Para os jovens submetidos ao regime de desempenho que emergiu dessas reformas, os efeitos dessas mudanças, embora já traçados em termos de suas primeiras consequências (REAY; WILIAM, 1999), provavelmente não serão totalmente conhecidos por geraçóes, especialmente por terem sido expostos a tal regime em tão tenra idade. ${ }^{4}$ De qualquer forma, há, na Inglaterra, evidências substanciais de ansiedade, automutilação e outros problemas para os jovens, caracterizados como estando relacionados à sua saúde mental, que foram diretamente associados a essas reformas. (GILBERT et al., 2009; SIMM et al., 2010)

\section{Reformas aceleradas}

Após 18 anos de administraçóes conduzidas por conservadores, centradas na reforma educacional neoliberal e neoconservadora, foi amplamente antecipado que a eleição de um governo do New Labour conduziria a uma reversão ou protelação dos esforços de reforma anteriores. No entanto, no campo da educação, a tão chamada e tão aclamada 'terceira via' da reforma do New Labour não era sempre tão fácil de ser discernida. Isso se deve ao fato de que muito do processo de reforma sob o New Labour foi construído sobre as bases das reformas dos anos 1980 e deu continuidade a seus principais fundamentos. Não obstante, os governos do New Labour podem ser considerados como aqueles que reafirmaram um compromisso com a educaçáo com financiamento público por meio de uma série de investimentos que levaram, em particular, a aumentos significativos nos salários dos professores e a programas de construção de escolas em larga escala, que buscaram corrigir um legado de baixo investimento e controles rígidos de gastos com a educação por parte dos governos conservadores.

No entanto, sua abordagem dominante foi tomar como base o Ato de 1988. Isso significa que não apenas os princípios subjacentes ao Ato de 1988 (que combinava a mercantilização com a centralização curricular e a avaliação) foram mantidos nos governos do New Labour durante este período, mas que foram intensificados e acelerados por meio de uma gama de iniciativas políticas chave. É de particular interesse a criação dos programas de Academias e outras tentativas de promover a mercantilização por intermédio da ampliação da diversidade escolar e escolha de escolas. Por todo esse período, um aspecto chave do discurso do New Labour, que incita comparação direta com as reformas anteriores dos anos 1980, e aumentaram a sensação de continuidade com o passado recente, foi um uso marcante do discurso dos 'padróes educacionais'. Isso não só apelava à vontade dos políticos trabalhistas de continuar a prática de aplicar discursos originários do pensamento neoconservador, mas também enfatizava o continuado poder da 
mídia impressa via até onde o New Labour estava disposto a ir para tentar evitar o que era visto como associaçóes tóxicas com a crise dos anos 1970. (CAMPBELL, 2011)

Assim, em um nível, a abordagem do New Labour em relação à reforma educacional pode ser vista como uma abordagem na qual um discurso de fé renovada na escolarização pública foi re-asseverado por intermédio de amplas injeçóes de dinheiro público, além de consideráveis tentativas de melhorar a qualidade e eficácia das escolas via estratégias nacionais, aliadas à invocação disciplinar de padróes. Tomada isoladamente, esta dimensão do programa de reforma do New Labour teria sido uma intervenção ambiciosa à medida que a pressão tornou-se ainda maior sobre as escolas, professores e alunos, conforme eles eram coagidos a ter um desempenho dentro de parâmetros cada vez mais restritos, a níveis cada vez maiores, em relação a seu desempenho em testes nacionais. Essa virada marcadamente performativa na educação no final dos anos 1990 e 2000, embora não seja uma nova característica da reforma educacional, alcançou níveis até então nunca vistos sob o New Labour, quando a abordagem de "deliverology" (BARBER, 2007) para a reforma dos serviços públicos foi implantada em um sistema escolar rico em dados e, segundo a qual, as metas para a melhoria do desempenho em relação aos níveis nacionais se tornaram uma característica dominante da vida escolar no âmbito institucional, da sala de aula e dos alunos.

Obviamente, contudo, esta tentativa de elevar os padróes por intermédio de mecanismos de oferta ou entrega de serviços públicos era apenas uma das tendências da abordagem do New Labour para a reforma educacional. Também estava presente uma ênfase neoliberal persistente sobre mercados, competição e poder de escolha no campo da educação que foi significativamente ampliada pelo New Labour por meio da introdução de Academias como escolas independentes do Estado, com financiamento privado e, portanto, fora do controle das autoridades locais. ${ }^{5}$ Além disso, o convite feito a todas as escolas de ensino médio para que se tornassem instituiçóes especializadas, representou uma tentativa ampliada e mais determinada de desmembrar o sistema escolar abrangente, comum, que havia se desenvolvido desde o final dos anos 1950. O programa das Academias, em particular, foi muito mais abrangente do que seu predecessor, sob as administrações Conservadoras, o City Technology College, em que apenas 15 escolas foram eventualmente criadas. Portanto, a abordagem diretiva, centralizada e baseada na métrica, visando "elevar os padróes" nas escolas, foi complementada sob o New Labour, por meio de um contínuo comprometimento com a mercantilização e o desenvolvimento do poder de escolha. Desta forma, a alteração de um modo de educação como um direito civil, welfarista, que teve início durante os anos de 1980, foi entusiasticamente continuado pelo New Labour.

A eleição de um governo de coalizão Conservador/Democrático Liberal (2010-2015) na Inglaterra foi, novamente, notável, principalmente devido a sua 
convergência com administraçóes prévias desde 1979. Curiosamente, quase quarenta anos desde a emergência da "crise" educacional da década de 1970, o discurso sobre padróes permaneceu predominante por todo esse estágio da reforma. $\mathrm{Na}$ verdade, a reforma neoconservadora, ligada a idéias socialmente autoritárias sobre valores e conhecimentos sancionados desfrutou de um ressurgimento durante esta era, com o Secretário de Estado para a Educação tentando intervir pessoalmente sobre quais livros eram lidos pelas crianças nas disciplinas de Literatura Inglesa e História - e, talvez ironicamente, no contexto de clamores cada vez mais altos pela independência da Escócia -, com tentativas de instilar valores britânicos nos alunos que frequentavam as escolas na Inglaterra. (MUIR, 2014)

De maneira correspondente, as dimensôes neoliberais da NGP, neste contexto, foram aceleradas ao ponto de, durante o período de 2010-2014, mais de metade de todas as escolas de ensino médio, ou seja, cerca de 3.000, se converteram para o status de Academia. Em conjunto com a criação das chamadas "escolas livres", que também permaneceram independentes do controle de autoridades locais eleitas democraticamente, isso significou que um sistema educacional antes gerido publicamente, havia sido quebrado a tal ponto que a NGP cessou de ser um descritor útil dos processos em jogo. Consequentemente, uma era pós-NGP pode ser vista como tendo passado a existir, em comum com o que ocorreu em outras partes do setor público no Reino Unido. A Educação passou a ser gerida de forma privada, embora sendo ainda um sistema principalmente financiado pelo Estado, com o potencial para a rápida conversão para financiamento privado e financiamento privado estendido.

\section{Compreendendo a permanente instabilidade na educação inglesa}

A partir do que foi exposto acima, pode-se perceber que tem havido uma 'revolução permanente' (POLLITT; BOUCKAERT, 2000) da reforma educacional relacionada à NGP na Inglaterra. Isso teve início como uma tentativa conduzida pela Nova Direita de reorganizar o setor educacional como parte de uma série mais ampla de reformas da NGP. Seguindo sucessivas mudanças de governo, isso se metamorfoseou em uma era pós-NGP, na qual a provisão educacional de propriedade e gestão públicas está rapidamente sendo transferida para interesses privados. Esse processo de reforma tem sido contínuo e, apesar de algumas diferenças entre administraçóes políticas sucessivas, tem sido baseada em prescriçóes políticas marcadamente semelhantes, baseadas em processos de intensificação, expansão e aceleração que tiveram início nos anos 1980. Ainda assim, apesar das semelhanças de abordagem, o processo de reforma não conduziu a uma solução educacional estável; ao contrário, é um processo onde a instabilidade tem 
sido vivenciada por professores e jovens em um processo sentido, com demasiada frequência, como "re-desorganização". (POLLITT, 2007) Em parte, essa instabilidade pode ser explicada diretamente pela permanência mesmo do processo de reforma em si, no qual escolas, professores e jovens têm vivenciado mudanças constantes e por vezes perturbadoras. No entanto, a permanente instabilidade da educação na Inglaterra também pode ser localizada nas tensóes mais profundas subjacentes às reformas em si. As tensôes entre as abordagens neoconservadora e neoliberal para a reforma educacional na Inglaterra, às quais nos referimos nas seçôes antecedentes neste artigo, são uma de tais fontes.

Tais tensões não estão somente presentes nas contradiçóes entre os neoliberais e os neoconservadores; elas podem ser identificadas dentro das tensóes mais amplas no próprio discurso da NGP. Uma ênfase no desempenho do setor público dentro da NGP (POLLITT; BOUCKAERT, 2000) levou à criação de uma nova métrica de reforma. Essas métricas foram destinadas a permitir o controle da atividade do setor público por intermédio de mensurações e a subsequente recompensa e punição daqueles que atingiram ou transgrediram as quantificações de desempenho prescritas. Simultaneamente, a NGP destinava-se a desencadear formas novas e inovadoras de possibilitar a entrega de serviços nas quais os cidadãos, recém-posicionados como clientes, seriam os supostos recipientes de níveis de serviço aprimorados. Na versão anterior da NGP, descrita como "dura" (FERLIE; GERAGHTY, 2005), a ênfase discursiva recai sobre o controle das instituiçóes públicas e seus funcionários em um ambiente de baixa confiança e com níveis mais baixos de autonomia para os servidores. Na versão posterior, mais "branda" (FERLIE; GERAGHTY, 2005), da NGP, a ênfase maior recai sobre como possibilitar a emergência de mudança dentro do setor público por meio da criatividade, inovação e empreendedorismo, com níveis de confiança concomitantemente mais altos. Assim, contidos na NGP, estavam discursos contraditórios de alta e baixa confiança, autonomia e controle, criatividade e prescrição. Interessantemente, foi a versão branda na NGP que a colocou, discursivamente, em um ponto mais distante do recém ultrapassado discurso da administração pública e burocracia que buscava substituir, porém foi a versão mais dura da NGP que continuou a dominar as vidas dos professores, jovens e seus pais.

Um exemplo importante da forma pela qual essas tensões se manifestaram na Inglaterra, de certa forma alimentando a permanente instabilidade, foi por intermédio do aumento da liderança nas escolas inglesas. Como explicamos anteriormente, uma manifestação de um profissionalismo mais restrito para os professores, sob a NGP, foi fortemente ligada aos regimes de desempenho que haviam se desenvolvido nas escolas, conforme instituídos pelo programa da reforma. (HALL, 2013) Isso havia conduzido a uma onda de gerencialismo (GEWIRTZ, 2002) nas escolas na qual a mudança decretada, diretamente vinculada à agenda da reforma, estava em ascendência, e a autonomia dos professores estava em declínio. 
Esse desenvolvimento foi acompanhado pela ascensão simultânea de um discurso de liderança dentro das escolas, conforme manifestado de forma mais marcante pela criação do National College of School Leadership (NCSL) sob o New Labour (Hall et al., 2013). Inicialmente, essa guinada discursiva da gestão para a liderança enfocava uma forma de liderança transformadora, com os diretores como supostos "lone rangers" (SPILLANE; DIAMOND, 2007) ou líderes individuais dentro das escolas.

Esta guinada discursiva a favor da liderança, enfatizando a agência daqueles incumbidos da tarefa de fazer com que as reformas funcionassem dentro das escolas enquanto instituiçóes únicas, pode ser vista como estranha dentro do contexto de um esforço de reforma firmemente administrado, dirigido centralmente e direcionado pela métrica. Embora a posição histórica e legal dos diretores, com poderes significativos garantidos em seu papel, realmente tenha feito com que o modelo de líder único fosse mais compreensível, as pressóes para assegurar a reforma, no âmbito local, foram imensas que esses tempos estavam longe de serem ideais para a emergência, dentro das escolas, desses tipos de liderança imaginados, impulsionados por valores morais. (HARRIS, 2003; LEITHWOOD et al., 1999) Se a mudança para a liderança nesse clima era estranha, ainda mais estranha foi a posterior emergência da liderança distribuída como um discurso dominante (HALL et al., 2013) nas escolas. Sob esse modelo de liderança, grupos cada vez maiores de pessoas que atuavam nas escolas eram convidados a se imaginar como líderes, consequentemente disseminando as contradiçôes da guinada discursiva para a liderança a um grupo ainda maior de professores. Nessa guinada, uma versão mais dura, menos palatável da NGP, foi envolta por uma versão mais branda da NGP e, no contexto de uma reforma implacável e centralmente dirigida, uma versão praticamente inatingível. (HALL, 2013)

Correspondentemente, a NGP conferiu aos jovens, professores e escolas um conjunto contraditório de reformas que estão sendo atualmente "solucionadas" no contexto inglês por meio do desmantelamento, pós-NGP, de um sistema educacional público e por sua substituição por um sistema educacional privado no qual as escolas competem ferozmente em um mercado educacional onde os propósitos da educação são redutoramente simplificados a pontuações em testes. Nesse novo sistema de educação privatizado, a criatividade, a inovação e a autonomia estão localizadas nas novas "liberdades" desfrutadas pelos gestores escolares, que buscam posicionar suas instituiçóes em mercados educacionais locais. $\mathrm{O}$ controle e a prescrição estão principalmente ligados ao ensino e à aprendizagem, sujeitando os jovens e os professores a uma camisa de força pedagógica focada no desempenho. A instabilidade permanente parece determinada a continuar. 


\section{Notas}

1. Traduzido por Karin Quast.

2. N.T.: Termo relativo a um consenso welfarista entre os partidos Conservador e do Trabalho, que combinou os nomes de R. A. Butler e Hugh Gaitskell; ambos respectivos chanceleres do Exchequer.

3. O anverso disso nunca se aplicou no Reino Unido com escolas mantidas pelo Estado sendo oferecidas crédito discursivo de elite e disseminado pelos períodos economicamente bem-sucedidos.

4. O teste Key stage 1, por exemplo, era direcionado a crianças de seis a sete anos.

5. As autoridades locais se tornaram as principais responsáveis pelas escolas sob os termos do Ato de 1944 .

6. N.T.: "Lone ranger", ou cavaleiro solitário, é aquele que age por conta própria, sem consultar ou depender da aprovação de outros.

\section{Referências}

BALL, S. J. The teacher's soul and the terrors of performativity. Journal of Education Policy, n. 18,2003 , p. 215-228.

. Education PLC: Understanding Private Sector Particpation in Public Sector Education. Abingdon: Routledge, 2007.

BARBER, M. Instruction to Deliver. Tony Blair, Public Services and the Challenge of Achieving Targets. London: Politico's, 2007.

BRIGGS, A. The Welfare State in Historical Perspective. European Journal of Sociology, n. 2, 1961, p. 221-258.

CALLAGHAN, J. Speech at Ruskin College, Oxford, 18 October 1976. Times Educational Supplement, 22 October 1976, p. 1, 72.

CAMPBELL, A. The Alastair Campbell Diaries Volume One: Prelude to Power 1994-1997. London: Arrow Books, 2011.

CHRISTENSEN, T.; L/EGREID, P. Democracy and administrative policy: contrasting elements of New Public Management (NPM) and post-NPM. European Political Science Review, n. 3, 2011, p. 125-146.

CLARKE, J.; NEWMAN, J. The Managerial State, Power, Politics and Ideology in the Remaking of Social Welfare. London: Sage, 1997.

COX, A.; BOYSON, R. The Fight for Education: A Black Paper. London: Dent, 1975.

COX, A.; DYSON, C. Right for Education: A Black Paper. London: Critical Quarterly Society, 1999.

DAVIS, J. The Inner London Education Authority and the William Tyndale Junior School Affair, 1974-1976. Oxford Review of Education, v. 28, n. 2, 2002, p. 275-298. 
DUNLEAVY, P. et al. New public management is dead. Long live digital-era governance. Journal of Public Administration Research and Theory, v. 16, n. 3, 2005, p. 467-494.

EVETTS, J. New professionalism and new public management: changes, continuities and consequences. Comparative Sociology, v. 8, n. 2, 2009, p. 247-266.

FERLIE, E.; GERAGHTY, J. Professionals in Public Service organisations: Implications for Public Sector Reforming'. In: FERLIE, E.; LYNN JNR L.; POLLITT, C. (Eds.). The Oxford Handbook of Public Management. Oxford: Oxford University Press, 2005, p. $422-425$.

GAMBLE, A. Privatization, Thatcherism, and the British State. Journal of Law and Society, v. 16, n. 1,1988 , p. $1-20$.

GEWIRTZ, S. The Managerial School: Post-welfarism and Social Justice in Education. London: Routledge, 2002.

GILBERT, P. et al. The dark side of competition: how competitive behaviour and striving to avoid inferiority are linked to depression, anxiety, stress and self-harm. Psychology and Psychotherapy: Theory, Research and Practice, n. 82, 2009, p. 123-136.

HALL, D. Drawing a Veil over Managerialism: Leadership and the Discursive Disguise of the New Public Management. Journal of Educational Administration and History, v. 45, n. 3, 2013, p. 267-282.

HALL, D.; GUNTER, H.; BRAGG, J. The strange case of the emergence of distributed leadership in schools in England. Educational Review, v. 65, n. 4, 2013, p. 467-487.

HARRIS, A. Introduction: Challenging the Orthodoxy of School Leadership: Towards Alternative Theoretical Perspectives. School Leadership and Management, v. 23, n. 2, 2003 , p. $125-128$.

HARVEY, D. A Brief History of Neoliberalism. Oxford: Oxford University Press, 2005.

HOOD, C.; PETERS, G. The Middle Aging of New Public Management: Into the Age of Paradox? Journal of Public Administration Research and Theory, n. 14, 2004, p. 267-282.

LEITHWOOD, K.; JANTZI, D.; STEINBACH, R. Changing Leadership for Changing Times. New York and London: Taylor and Francis, 1999.

MUIR, H. Behold, Michael Gove, the Caesar of the Schooling System. The Guardian, London, 20/6/14.

OZGA, J. Governing education through data in England: from regulation to self-evaluation. Journal of Education Policy, v. 24, n. 2, 2009, p.149-162.

PERRYMAN, J. et al. Life in the Pressure Cooker - School League Tables and English and Mathematics Teachers' Responses to Accountability in a Results-Driven Era. British Journal of Educational Studies, v. 59, n. 2, 2011, p. 179-195.

POLLITT, C. New Labour's Re-disorganization: Hyper-Modernism and the Costs of Reform, a Cautionary Tale. Public Management Review, v. 9, n. 4, 2007, p. 529-543. 
POLLITT, C.; BOUCKAERT, G. Public Management Reform. Oxford: Oxford University Press, 2000.

REAY, D.; WILLIAM, D. 'I'll be a Nothing': Structure, Agency and the Construction of Identity through Assessment. British Educational Research Journal, v. 25, n. 3, 1999.

SIMM, R.; ROEN, K.; DAICHES, A. Primary school children and self harm: the emotional impact upon education professionals, and their understanding of why children self-harm and how this is managed. Oxford Review of Education, v. 36, n. 6, 2010, p. 677-692.

SPILLANE, J.; DIAMOND, J. Distributed Leadership in Practice. New York: Teachers College Press, 2007.

WHITTY, G. The New Right and the National Curriculum: State Control or Market Forces? Journal of Education Policy, v. 4, n. 4, 1989, p. 329-341.

WHITTY, G.; MENTER, I. Lessons of Thatcherism: Education Policy in England and Wales 1979-88. Journal of Law and Society, v. 16, n. 1, 1988, p. 42-64.

WALLACE, M. Discourse of derision: the role of mass media within the education policy process. Journal of Education Policy, v. 8, n. 4, 1993, p. 321-337.

WILIAM, D.; BARTHOLOMEW, H.; REAY, D. Researching the Socio-Political Dimensions of Mathematics Education. Mathematics Education Library, v. 35, 2004, p. 43-61.

WILSON, H. Purpose in Politics: Selected Speeches. London: Wiedenfeld and Nicolson, 1964.

Recebido em 21 de julho de 2015.

Aprovado em 28 de setembro de 2015.

DOI: http://dx.doi.org/10.1590/ES0101-73302015152454 